\section{Professional unity}

In her valedictory address, CMA's outgoing President Dr. Cindy Forbes also spoke about professionalism in the face of sometimes hostile governments, pressure-cooker schedules and continually changing technology.

"How will we move forward?" asked Forbes. "We will stand together as a profession, based on our common values, always putting patients first. We will support and respect each other as individuals, as colleagues who we care about. We will build trust by being trustworthy."

\section{Doctor burnout}

Physicians also took time to focus on their health during a session on strengthening resilience. Physicians can experience burnout, or other mental health problems, at any stage in their careers, said presenters.

Marie-Pier Bastrash, a medical student at McGill University presented preliminary results from a survey of 5000 medical students that indicated around $37 \%$ are burned out. It also found they have higher rates of anxiety and mood disorders than peers of similar age and education.

Delegates passed a motion asking CMA to undertake a nationwide study to analyze the working and practice conditions of medical students and residents.

\section{Climate change}

The annual meeting began with a plea from humanitarian Dr. James Orbinski, who presented a grim picture of the health effects of climate change. The cofounder of Médecins Sans Frontières Canada urged CMA to "step up and step out, to be genuinely courageous on climate change." Doctors have a professional responsibility to get involved, he added.

Forbes rose to the challenge, promising that by the 2017 annual meeting, CMA will be "well on its way to estab- lishing a new role in dealing with climate change."

\section{On legal pot}

Recreational marijuana is slated to be legal in 2017 and doctors want the federal government to keep it out of the hands of teenagers, according to the results of a CMA survey of 788 doctors presented at the meeting.

Nearly three out of four respondents $(72.2 \%)$ agreed the government should regulate levels of tetrahydrocannabinol in marijuana once the drug is legalized. Most respondents also agreed that nonhealth care structures like liquor stores should distribute the drug (56.1\%), and disagreed with providing the drug through health care settings like pharmacies $(57.4 \%)$ or by mail (64.9\%).

Go to cmajnews.com for complete coverage of the CMA Annual Meeting. - Barbara Sibbald, CMAJ

CMAJ 2016. DOI:10.1503/cmaj.109-5321

\title{
Misconduct saga rattles bone scientists
}

I n a saga that has shaken scientists who study bone health, the Canadian Institutes of Health Research (CIHR) has ruled that a University of Toronto medical school professor is guilty of a serious breach of federal research rules.

A committee appointed by Women's College Hospital in Toronto found that Dr. Sophie Jamal manipulated trial data to make the results look better, presented manipulated data to coinvestigators as if they were raw data, falsely accused a research assistant of manipulating data, and deleted records required for the hospital's forensic investigation. Jamal was the hospital's head of endocrinology and director of osteoporosis research until she resigned from the hospital and the university last year.

This is the first time a federal funding agency has named a scientist for a breach of the TriAgency Framework: Responsible Conduct of Research since the framework took effect in December 2011. CIHR also banned Jamal for life from receiving funds; she is the sixth scientist to receive a lifetime ban because of research violations.
Coauthors have so far retracted two papers on which she was an author, and have asked a journal to retract another. A university committee is reviewing as many as 50 other articles. One retraction notice said Jamal had "declined to provide any comments." She did not respond to interview requests from $C M A J$.

Some colleagues are skeptical about the ruling. "We all know Sophie; we all work with her; we all thought she was of high moral standing and had high ethics," said Dr. Thomas Nickolas, a kidney specialist at Columbia University College of Physicians and Surgeons in New York City.

Dr. David Goltzman, a senior scientist at McGill University, who led a long-term study underlying one of the retracted articles, called Jamal "extremely well-trained, extremely talented," and said the situation is "tragic."

The Women's College investigation focused on a study testing the effects of different nitrate drugs on bone health, an area Jamal had worked in since the 1990s when she was at the University of California, San Francisco (UCSF). Early on, reviewing data that others had gathered, she discovered that women taking nitrate drugs had higher bone densities, a finding she published in 1998 with UCSF's Dr. Steven Cummings, a leader in osteoporosis research and her mentor.

Apart from the stint at UCSF, Jamal did nearly all of her training at the University of Toronto and returned there to continue her research. Her first trial to test a nitrate drug against placebo, published in 2004 in the Journal of Bone and Mineral Research, had positive findings that suggested nitrates may be useful for the prevention of postmenopausal osteoporosis.

By the late 2000s, the search for a safer drug for women with fragile bones was pressing because of emerging information about the risks of drugs typically prescribed for osteoporosis. Jamal's next trial with nitrates resulted in her highestprofile publication, a 2011 paper in the Journal of the American Medical Association (JAMA). With Cummings and Dr. Richard Eastell, an osteoporosis 
expert at the University of Sheffield in the United Kingdom, she studied older women who applied nitroglycerine ointment nightly for two years.

The trial showed a positive effect on bone health and some of the data were so impressive, according to Dr. Sundeep Khosla, an osteoporosis expert at the Mayo Clinic, Minnesota, that when the United States National Institutes of Health (NIH) asked him to review Jamal's proposal to plan a follow-up trial to see if nitrate drugs could prevent fractures, he argued strongly for it. In 2012, Jamal's team secured funding for the planning phase of a study, including more than $\$ 260000$ from CIHR. That is the study - coauthored with Jamal's longtime collaborators, Cummings and Eastell - that prompted the investigation, after the California Pacific Medical Center Research Institute, where Cummings works, filed a complaint with the University of Toronto.

The JAMA paper had reported that tests for bone turnover markers showed nitroglycerine treatment increased a marker for bone formation found in blood, and decreased a marker of bone resorption found in urine - results that, combined with other data gathered on the women, suggested nitrates could lower a woman's risk of fractures. But the drug also caused bad headaches, so the planning study was assessing the effects of five different drugs "to select the best nitrate preparation" for a future trial.

Eastell's group was measuring the bone turnover markers "blind to treatment assignment" and sent Jamal the results in a spreadsheet, Eastell told $C M A J$ in an e-mail. Jamal "analyzed the data but there was an odd result," so he asked her to send the data she held with the treatment codes, "and noted there were changes to the data." $\mathrm{He}$ and Cummings agreed they had to report their concerns.

Following an inquiry by the university and the hospital, the hospital appointed a three-person committee to conduct its first misconduct investigation, according to Dr. Paula Rochon, Women's College Hospital's vice-president of research. Last October, the hospital released a letter announcing Jamal's resignation and the committee's finding of "systematic data manipulation." Then in January, Eastell,

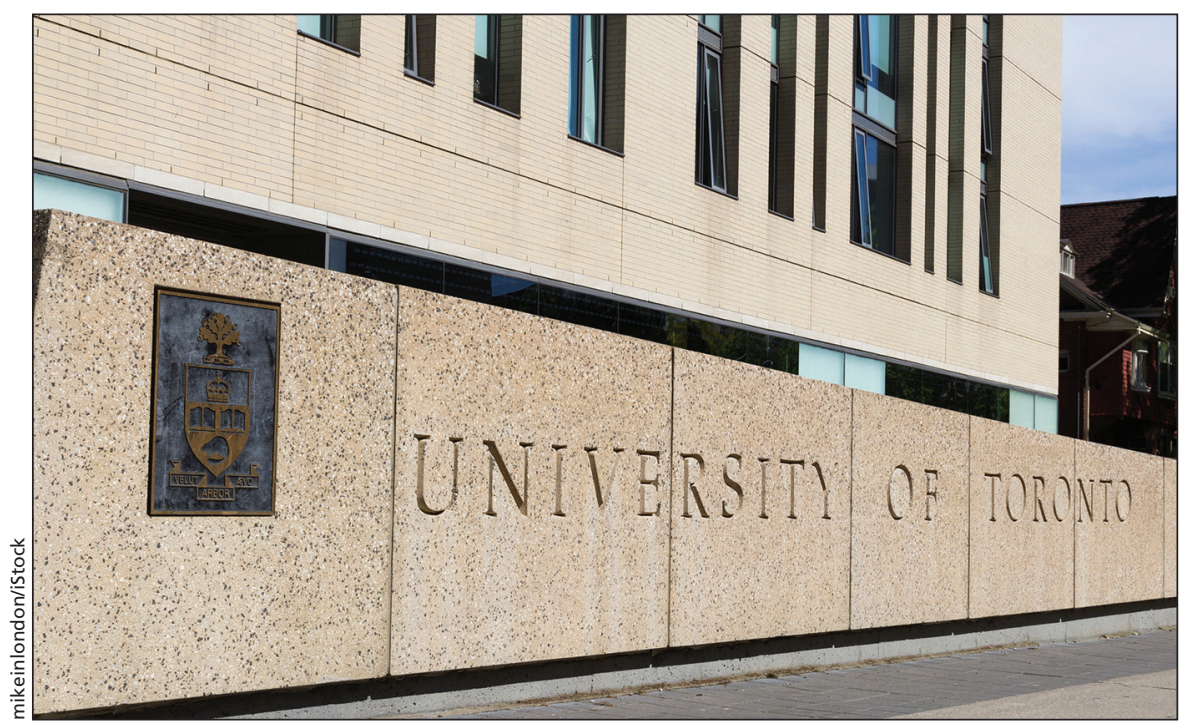

Dr. Sophie Jamal of the University of Toronto was found to have breached terms of CIHR's TriAgency Framework: Responsible Conduct of Research.

Cummings and another coauthor retracted the 2011 JAMA paper and in a retraction letter to JAMA's editors, wrote that the committee "concluded, based on objective evidence, that Dr. Jamal had falsified and/or fabricated data and used that data for statistical analysis."

When researchers with the Canadian Multicentre Osteoporosis Study heard about the retraction in JAMA, they undertook their own investigation because Jamal was their study's site codirector in Toronto, said Goltzman, the principal investigator. They contacted Jamal about six papers on which she was lead investigator but she told them that the data were unavailable, so scientists from outside Ontario redid the analyses using data from the study's central repository. They could not reproduce results published in two of the papers, "so that's when we said these are possibly flawed data and we didn't want to take a chance," Goltzman said. The group issued two letters of retraction, one for a 2010 paper in the American Journal of Kidney Diseases that was retracted in June, and another for a 2009 paper in Osteoporosis International that the journal has yet to retract.

More retractions could follow: a committee of scientists at the University of Toronto and affiliate hospitals is reviewing more than 50 articles for which Jamal was either the first or senior author, according to Althea
Blackburn-Evans, the university's director of media relations. "We're going through her publications one by one to determine if there are any further concerns," said Rochon, committee cochair.

Jamal has left science, though she remains in practice in the Toronto area; the investigation did not find that any participants in her studies had been exposed to harm, although the hospital notified participants that information they'd received about the research could be "inaccurate." Jamal must pay back the funds she received for the planning phase study, says CIHR spokesperson David Wolkowski. Meanwhile, the hospital is keeping the investigative report confidential, and Jamal's former colleagues are struggling to understand what may have happened.

Two Toronto scientists who did not want to be named said that Jamal alone was analyzing the data in her papers, which could introduce a bias toward what she hoped to find. Khosla also reported having heard that, when it came to assessing the final results, the JAMA paper lacked the safeguard of having many people look at the data independently. "I think what happened here is Dr. Jamal had control over everything, including the statistical analyses," he said, "and that, in retrospect, just should not be allowed to happen." - Miriam Shuchman MD, Toronto, Ont.

CMAJ 2016. DOI:10.1503/cmaj.109-5314 